\title{
Persepsi Konsumen Muslim terhadap Sertifikasi Halal pada De Dapoer Rhadana Hotel Kuta Bali
}

\author{
Nur Dwi Astutik*, Ahmad Ahsin Kusuma Mawardi, Agus \\ Mahardiyanto \\ Fakultas Ekonomi, dan Bisnis, Universitas Jember, Jawa \\ Timur, Indonesia \\ *Corresponding author: nurdwiastutik0603@gmail.com
}

\author{
Article history \\ Received, 03 April 2021 \\ Revised, 20 Juli 2021 \\ Accepted, 28 July 2021
}

\begin{abstract}
De Dapoer-Rhadana Hotel Kuta Bali is one of the restaurants that has been certified halal in its products. As consumers especially muslim consumers should be more vigilants, selective and observant in choosing restaurants while in Bali that are halal to eat and thayyib. The method used is this study is qualitative descriptive that aims to know the muslim consumer's perception of halal certification of De Dapoer - Rhadana Hotel Kuta Bali. The results of this study showed that the muslim consumer perception of halal certification in De Dapoer - Rhadana Hotel Kuta Bali assumer or perception that halal certification is important. Because the respondents know that to guarantee the halalness of product by means of halal certification labels. The final results of the study showed that consumers consider halal certification is important.
\end{abstract}

Keyword: De Dapoer - Rhadana Hotel Kuta Bali, Sertifikasi Halal, Muslim Consumers

\begin{tabular}{|c|c|}
\hline \\
\hline \multirow{5}{*}{\multicolumn{2}{|c|}{$\begin{array}{l}\text { uslim harus lebih waspada, selektif dan jeli dalam memilih restoran saat berada di } \\
\text { ng halal untuk dimakan dan thayyib. Metode yang digunakan dalam penelitia } \\
\text { alah deskriptif kualitatif yang bertujuan untuk mengetahui persepsi konsumen mi } \\
\text { hadap sertifikasi halal De Dapoer - Rhadana Hotel Kuta Bali. Hasil penelitia } \\
\text { enunjukkan bahwa persepsi konsumen muslim terhadap sertifikasi halal yang ada }\end{array}$}} \\
\hline & \\
\hline & \\
\hline & \\
\hline & \\
\hline \multicolumn{2}{|c|}{ e Dapoer - Rhadana Hotel Kuta Bali beranggapan atau berpersepsi bahwa sertif } \\
\hline \multicolumn{2}{|c|}{ alal itu penting. Karena responden mengetahui bahwa untuk menjamin kehalalan } \\
\hline \multirow{2}{*}{\multicolumn{2}{|c|}{ roduk dengan cara adanva label sertifikasi halal. Hasil akhir penelitian menuniu }} \\
\hline & \\
\hline \multicolumn{2}{|c|}{ T } \\
\hline & \\
\hline & \\
\hline & \\
\hline & \\
\hline
\end{tabular}




\section{Pendahuluan}

Konsumen muslim merupakan orang yang membeli atau memakai suatu barang atau produk yang halal dan baik. Karena dalam hal ini apabila sudah dikatakan baik dan halal bagi orang muslim tentunya aman di konsumsi juga bagi non-muslim. Untuk memilih hotel terutama restoran yang terjamin kehalalannya adalah dengan mengetahui bahwa restoran tersebut sudah terdapat sertifikasi halal.Sertifikasi halal didefinisikan sebagai kegiatan pengujian secara sistematik untuk mengetahui apakah barang yang di produksi perusahaan tersebut telah memenuhi ketentuan halal atau belum. Kemudian, hasil dari kegiatan sertifikasi halal apabila produk telah memenuhi ketentuan sertifikasi halal maka akan diterbitkannya sertifikasi halal.

Undang-Undang Republik Indonesia No. 33 Tahun 2014 tentang jaminan produk halal mengatakan bahwa sertifikat halal adalah pengakuan kehalalan suatu produk. Berdasarkan fatwa MUI bahwa kehalalan suatu produk sesuai dengan prinsip-prinsip syariah dan merupakan syarat dalam pencantuman label halal dalam setiap produk makanan, minuman, obat-obatan dan kosmetika. Sertifikasi halal diterbitkan apabila produk sudah sesuai memenuhi ketentuan sebagai produk halal.

Setiap umat islam diwajibkan mengonsumsi makanan yang halal. Sertifikasi halal menjadi penjaminan kehalalan suatu produk dari bahan yang digunakan. Sertifikasi halal menjadi sesuatu yang penting dan perlu diperhatikan oleh konsumen sebelum memilih makanan yang akan dibelinya. Salah satu cara yang dapat dilakukan konsumen yaitu memulai sejak dini mengonsumsi segala sesuatu yang sudah pasti kehalalannya dengan memperhatikan ada atau tidaknya sertifikat halal pada produk yang ada di restoran. Dalam hal ini ada bebererapa yang harus diwaspadai terkait dengan bahan yang digunakan, proses pembuatan, campuran yang digunakan dalam pembuatan hingga sampai pada tangan konsumen yang menjadi tanggung jawab produsen maupun pedagang. Permasalahannya dalam kehidupan masyarakat muslim sebagai konsumen kurang memperdulikan bahkan dianggap tidak penting pencantuman sertifikat halal produk yang disajikan oleh produsen ke konsumen, padahal sertifikasi halal menjadi penjaminan kehalalan suatu produk dari bahan yang digunakan sesuai dengan prinsip bisnis syariah.

Kebutuhan mendasar manusia selain tempat tinggal dan pakaian adalah makanan dan minuman. Dalam islam, mengonsumsi makanan tidak hanya sekedar mengonsumsi makanan saja namun ada juga aturan syariat yang mengatur tentang makanan yang harus dimakan. Allah berfirman dalam Q.S. Abasa[80] ayat 24 yang artinya : "Maka hendaklah manusia itu memerhatikanmakannya".

Wisatawan yang berlibur di Bali tidak hanya non-muslim tetapi juga orang muslim sehingga dalam mencari tempat makan sering mengalami keraguan mengenai halal tidaknya makanan yang akan dikonsumsinya tersebut. Hal ini dikarenakan penduduk Bali yang mayoritas masyarakatnya non-muslim dapat menimbulkan berbagai pertanyaan mengenai makanannya halal atau tidak dan apakah aman untuk dikonsumsi bagi orang muslim atau tidak. Dalam hal ini wisatawan muslim mencari yang sudah aman untuk di konsumsi dan jelas kehalalan baik cara pengelolaannya, penyajiannya maupun produknya. De Dapoer - Rhadana Hotel Kuta Bali menyediakan makanan yang sudah jelas kehalalannya dan memiliki sertifikasi halal MUI. Sehingga wisatawan yang makan di De Dapoer - Rhadana Hotel Kuta Bali tidak perlu khawatir akan makanan yang disajikan dan aman tidaknya untuk di konsumsi. 
Rhadana Hotel Kuta Bali merupakan hotel bintang 4 yang pas untuk para wisatawan muslim yang akan atau sedang berkunjung ke Bali. Rhadana Hotel Kuta Bali tidak hanya sebagai hotel ramah muslim namun dibuktikan juga dengan menyediakan restoran halal beserta sertifikat halal MUI. Restoran tersebut bernama De Dapoer - Rhadana Hotel Kuta Bali yang mana restoran ini dirancang menyerupai dapur gaya lama namun dengan suasana masa kini. Makanan dan minuman yang ada di De Dapoer - Rhadana Hotel Kuta Bali dikategorikan sebagai resep asli ibu dan nenek dari pemiliknya. Hidangan yang disajikan merupakan hidangan asli Indonesia yang dibalut dengan sentuhan modern. Adanya sertifikat halal dari MUI dapat dikatakan sebagai kekuatan dan keunikan tersendiri bagi De Dapoer - Rhadana Hotel Kuta Bali. Dengan adanya sertifikat halal MUI dibuat dengan tujuan untuk melindungi konsumen yang makan di restoran tersebut dan tentunya agar konsumen merasa aman dan nyaman saat mengonsumsinya.

Hasil dari penelitian yang dilakukan oleh Meika Wahyuni yang berjudul Persepsi Konsumen Muslim Terhadap Sertifikasi Halal (Studi Kasus Pada PT. Rocket Chiken Indonesia Cabang Bojo Kendal) menyatakan bahwa sebanyak 10 informanyaitu $31,25 \%$ berpersepsi (menganggap) bahwa sertifikasi halal itu penting dan sebanyak 22 orang yaitu 68,75 berpersepsi menganggap bahwa sertifikasi halal itu tidak penting. ${ }^{1}$

Hasil dari penelitian yang dilakukan oleh Nurhayati Persepsi Produsen dan Konsumen Muslim Terhadap Sertifikasi Halal (Studi Kasus Pada Produsen dan Konsumen Muslim Bakso Gibras Cabang Ponorogo) menyatakan bahwa Persepsi produsen sedikit paham dan beranggapan sertifikat halal termasuk penting. Sedangkan untuk persepsi konsumen muslim tidak menganggap bahwa sertifikasi halal itu penting. ${ }^{2}$

Hasil dari penelitian yang dilakukan oleh Nadia Wulan Daru dan Moch.Khoirul Anwar Persepsi Konsumen Muslim Terhadap ProdukMs Glow Yang Bersertifikasi Halal Di Surabaya menyatakan bahwa ada dua persepsi konsumen muslim yaitu ada konsumen yang menginginkan untuk diberikannya sertifikasi halal pada semua jenis produk Ms Glow da n ada yang tidak mempermasalahkan sertifikasi halal pada semua jenis produk Ms. Glow. ${ }^{3}$

Pengertian persepsi menurut Walgito yang mendefinisikan persepsi merupakan proses diterimanya stimulus yang didahului oleh proses pengindraan. ${ }^{4}$ Menurut Schiffman dan Kanuk (2010), terdapat tiga dimensi dalam persepsi yaitu:

1. Kognitif berupa pengetahuan tentang objek yang akan dipersepsi;

2. Afektif merupakan gambaran perasaan individu suka atau tidak suka terhadap objek;

3. Konatif merupakan kecenderungan bertindak dengan cara tertentu terhadap objek.

Berdasarkan uraian yang dijelaskan diatas, maka yang menjadi fokus dalam artikel ini mengenai persepsi konsumen muslim terhadap sertifikasi halal di DeDapoer Rhadana Hotel Kuta Bali baik dari sisi pengetahuan terjaminnya kehalalan produk, keyakinan jaminan halal produk dan melakukan tindakan mengonsumsi produk halal

\footnotetext{
${ }^{1}$ Meika, Wahyuni, Persepsi Konsumen Muslim Terhadap Sertifikasi Halal. Skripsi. Semarang : Jurusan Ekonomi Islam Fakultas Ekonomi dan Bisnis Universitas Islam Negeri Walisongo, 2015.

${ }^{2}$ Nurhayati, Persepsi Produsen dan Konsumen Muslim Terhadap Sertifikasi Halal. Skripsi. Ponorogo : Jurusan Hukum Ekonomi Syariah Fakultas Syariah Institut Agama Islam Negeri, 2018.

${ }^{3}$ Nadia Wulan Daru, Moch. Khoirul Anwar, Persepsi Konsumen Muslim Terhadap Produk MS Glow Yang Bersertifikat Halal di Surabaya. Jurnal Ekonomi Islam. Vol. 2 No. 2 Hal. 15-24. Surabaya: Program Studi Ekonomi Islam Fakultas Ekonomi Universitas Negeri Surabaya, 2019.

${ }^{4}$ Walgito, Pengantar Psikologi Umum, Yogyakarta : Andi Offset, 2002, p. 87-88.
} 
terhadap sertifikasi halal di De Dapoer - Rhadana Hotel Kuta Bali.

Manfaat penelitian ini yaitu memberikan pengetahuan dan pemahaman kepada konsumen muslim agar tidak dalah dalam memilih rumah makan maupun makanan yang diperbolehkan dalam syariat islam

\section{Metode Penelitian}

Penelitian ini mengggunakan jenis penelitian deskriptif kualitatif dan teknik data yang digunakan adalah trianggulasi menurut Lexy J. Moleong (2002). ${ }^{5}$ Penelitian ini dilakukan secara langsung di De Dapoer yang merupakan restoran yang ada di Rhadana Hotel Kuta Bali dan berlokasi di Jalan Raya Kuta No.88 - Kuta - Kabupaten Badung - Bali, karena penelitian ini bertujuan ingin mengetahui persepsi konsumen muslim yang ada di De Dapoer terkait dengan sertifikasi halalnyadan sesuai dengan fenomena yang sedang terjadi dilapangan, waktu penelitian ini dimulai dari bulan November 2020 - Januari 2021.

Sumber data yang digunakan dalam penelitian ini ada dua yaitu data primer dan data sekunder. Metode pengumpulan data dalam penelitian ini yaitu wawancara mendalam atau in- depth interview. Teknik analisis data dalam penelitian ini menggunakan dua pendekatan yaitu penelitian sebelum di lapangan dan penelitian selama di lapangan. Penelitian sebelum di lapangan menurut Sugiono (2008), analisis telah dimulai sejak menjelaskan dan merumuskan suatu masalah sebelum terjun ke lapangan sampai dengan penulisan hasil penelitian. ${ }^{6}$ Dalam penelitian ini sebelum terjun di lapangan tempat observasi, peneliti melakukan analisis berbagai data yang berkaitan dengan sertifikasi halal di De Dapoer - Rhadana Hotel Kuta Bali baik berupa jurnal, skripsi, tesis, buku, majalah, artikel maupun tulisaan yang berada di laman web-site. Penelitian selama di lapangan menurut Miles dan Huberman, ada tiga tahap yaitu pertama reduksi data berdasarkan hasil observasi yang dilakukan melalui wawancara dengan pihak De Dapoer - Rhadana Hotel dan konsumen muslim terkait dengan persepsinya terhadap sertifikasi halal. Dokumentasi yang telah didapatkan, buku catatan dan rekaman suara hasil wawancara yang dapat dilakukan untuk memperoleh data yang dibutuhkan dalam penelitian ini. Peneliti melakukan pemilihan data sesuai dengan tujuan dalam penelitian ini yaitu untuk mengetahui persepsi konsumen muslim terhadap sertifikasi halal yang ada di De Dapoer - Rhadana Hotel Kuta Bali. Kedua, penyajian data dimana yang sering digunakan selain dalam bentuk naratif, bisa juga dalam bentuk grafik, matriks dan uraian singkat. Ketiga, penarikan kesimpulan. ${ }^{7}$

Keabsahan data dalam penelitian ini menggunakan dua teknik trianggulasi yaitu triangulasi metode dan triangulasi sumber. Triangulasi metode untuk menguatkan datadata yang didapatkan dari wawancara, observasi dan dokumentasi. Teknik trianggulasi sumber data dilakukan dengan cara memeriksa data dari sumber yang berbeda dengan teknik yang sama. Hal tersebut dapat dicapai dengan membandingkan hasil wawancara, observasi dan dokumentasi yang berkaitan dengan persepsi konsumen muslim pada De Dapoer - Rhadana Hotel Kuta Bali. Dengan menggunakan triangulasi sumber data, peneliti bisa membandingkan informasi yang diperoleh melaui sumber yang berbedabeda namun dengan teknik yang sama yaitu wawancara. Dalam penelitian kualitatif,

\footnotetext{
${ }^{5}$ Lexy J. Moleong, Metodologi Penelitian Kualitatif. Bandung: PT. Remaja Rosdakarya, 2009.

${ }^{6}$ Sugiono, Memahami Penelitian Kualitatif. Bandung : Alfabeta, 2008.

${ }^{7}$ Matthew B. Milles, Michael A Haberman , Analisis Data Kualitatif. Tjetjep Rohendi Rohini, Penerjemah. Jakarta : Universitas Indonesia. Terjemah dari : UI- PRESS, 2009.
} 


\section{Persepsi Konsumen Muslim terhadap Sertifikasi Halal \\ pada De Dapoer Rhadana Hotel Kuta Bali}

data dikatakan valid apabila tidak ada berbedaan antara sebenarnya yang terjadi pada objek penelitian dengan apa yang diteliti

\section{Hasil dan Diskusi}

Rhadana Hotel merupakan sebuah unit usaha jasa akomodasi ramah bagi wisatawan muslim dan non-alkohol, menjual dan memproduksi masakan, minuman etnik Indonesia bertaraf internasional, memiliki usaha yang berbeda dengan jasa akomodasi lainnya karena keunikan yang dimiliki Rhadana Hotel yaitu sebuah terobosan, berani tidak menyediakan alkohol, berpinsip dalam memperhatikan keamanan produk makanan dan minuman, terhindar dari hal-hal yang menyebabkan mudharat, menjaga kedamaian dan memberikan kenyamanan bagi pengunjung yang ada disana, menjamin suasana ramah, beretika serta bertoleransi.

De Dapoer dirancang dan dibangun menyerupai gaya lama dengan suasana modern masa kini. De Dapoer dipenuhi dengan memorabilia dan mengingatkan akan kehidupan pemilik dalam konsepnya. De Dapoer menonjolkan karakter dengan furnitur kayu tua yang memberikan kehangatan dan memberikan rasa nyaman bagi semua tamu. De Dapoer merupakan restoran yang memiliki sertifikat halal MUI (Majelis Ulama Indonesia) yang menyediakan makanan dan minuman halal. hidangan yang disajikan dikategorikan sebagai resep asli ibu dan nenek dari pemiliknya sehingga menghasilkan hidangan asli Indonesia yang dibalut dengan sentuhan modern. De Dapoer merupakan sebuah permata tersembunyi. Dalam hal ini kenyamanan yang diutamakan dari segi makanan dan minuman adalah restoran halal. Agar konsumen saat makan lebih nyaman dan merasa nyaman dalam mengonsumsi makanan halal karena di Bali susah menemukan makanan halal dan De Dapoer menjadi solusinya.

Persepsi dapat didefinisikan sebagai cara pandang seseorang terhadap apa saja yang ada di lingkungannya. Persepsi merupakan kemampuan otak dalam menerjemahkan stimulus yang masuk ke dalam alat indera manusia. Terbentuknya persepsi seseorang terhadap suatu objek berdasarkan situasi yang sedang dihadapinya sehingga menyebabkan cara pandang setiap orang berbeda-beda. Konsumen muslim merupakan seseorang yang membeli barang atau jasa yang halal dan thayyib. Sehingga persepsi konsumen muslim didefinisikan sebagai seseorang yang membeli barang atau jasa yang halal dan thayyib dalam memberikan makna terhadap apa yang diketahui dan lewat panca indera yang memberikan kesan kepada seseorang untuk memberikan makna terhadap lingkungannya. Proses yang dialami masing- masing konsumen bisa saja sama, namun yang dirasakan oleh masing-masing konsumen tentunya berbeda sehingga penafsiran terhadap sesuatu yang sama bisa saja berbeda dalam menanggapinya Seperti halnya persepsi konsumen muslim terhadap sertifikasi halal yang ada di De Dapoer - Rhadana Hotel Kuta Bali.

Persepsi konsumen muslim terhadap sertifikasi halal di De Dapoer- Rhadana Hotel Kuta Bali terjadi karena adanya pengetahuan yang dimiliki oleh konsumen muslim terkait dengan hal-hal yang diperbolehkan dan dilarang dalam syariat islam. Menurut teori Schiffman dan Kanuk (2010) menunjukkan bahwa seseorang dalam berpersepsi melalui beberapa tahapan proses. ${ }^{8}$ Kognitif berupa pengetahuan terjaminnya kehalalan produk, afektif berupa keyakinan jaminan halal pada produk dan konatif berupa melakukan tindakan mengonsumsi produk halal.Berikut ini adalah dimensi persepsi yang terjadi pada konsumen muslim terhadap sertifikasi halal di De Dapoer - Rhadana Hotel Kuta Bali diantaranya:

${ }^{8}$ Leon G Schifman, Leslie Lazar Kanuk, Perilaku Konsumen, Jakarta:PT Indeks Group Media, 


\section{Persepsi Konsumen Muslim atas Pengetahuan Terjaminnya Kehalalan Produk Terhadap Sertifikasi Halal di De Dapoer - Rhadana Hotel Kuta Bali Terkait Sertifikasi Halal}

Kognitif atau pengetahuan responden konsumen muslim tentang sertifikasi halal di De Dapoer - Rhadana Hotel Kuta Bali Berdasarkan hasil penelitian yang telah dijabarkan di atas, dapat diketahui bahwa alasan konsumen muslim memutuskan untuk membeli produk di De Dapoer - Rhadana Hotel Kuta Bali yang pertama yaitu menyediakan makanan dan minuman halal. Kedua yaitu sudah tersertifikasi halal, baik dan aman untuk dikonsumsi oleh konsumen muslim. Mengenai jaminan kehalalan produk di De Dapoer - Rhadana Hotel Kuta Bali pandangan responden sudah terjamin karena setelah seaching ada notifikasi bersertifikasi halal, non-alkohol dan sudah ada sertifikasi halal dengan mencari tahu di google.

\section{Persepsi Konsumen Muslim atas Keyakinan Jaminan Halal Produk Terhadap Sertifikasi Halal di De Dapoer - Rhadana Hotel Kuta Bali Terkait Sertifikasi Halal}

Afektif atau keyakinan responden konsumen muslim tentang sertifikasi halal di De Dapoer - Rhadana Hotel Kuta Bali dapat disimpulkan bahwa ada dua responden yang tidak menanyakan jaminan halal yang ada di De Dapoer - Rhadana Hotel Kuta Bali namun mereka percaya karena disana banyak pengunjung yang berpakaian hijab dan mencari tahu di google bahwa sudah tersertifikasi halal jadi memantapkan diri. Sedangkan tiga responden sudah pernah menanyakan jaminan halal pada karyawan seperti resepsionis dan koki dan respon dari karyawan baik dan ramah sehingga konsumen tambah yakin kalau memang De Dapoer - Rhadana Hotel Kuta Bali halal. Pandangan responden tentang sertifikasi halal adalah sertifikat yang membutikan tempat itu halal, menyediakan barang-barang halal, minuman dan makanan halal. ${ }^{9}$ Adapun responden yang beranggapan bahwa sertifikasi halal adalah sertifikat yang ditempel didinding, kehalalan produk atau makanan telah lulus uji, ditetapkan, dikeluarkan oleh MUI, dan kehalalannya sudah diketahui untuk menunjukkan bahwa produk dan restoran tersebut benar-benar halal serta terjamin kehalalannya.

\section{Persepsi Konsumen Muslim untuk Melakukan Tindakan Mengonsumsi Produk Halal Terhadap Sertifikasi Halal di De Dapoer - Rhadana Hotel Kuta Bali Terkait Sertifikasi Halal}

Konatif atau kecenderungan melakukan tindakan responden konsumen muslim tentang sertifikasi halal di De Dapoer - Rhadana Hotel Kuta Bali dapat disimpulkan bahwa para responden mengetahui di De Dapoer - Rhadana Hotel Kuta Bali sudah tersertifikasi halal dengan yang mencari tahu terlebih dahulu di google, internet, browsing, dan rekomendasi dari teman sehingga mereka tertarik untuk datang di De Dapoer - Rhadana Hotel Kuta Bali. Setelah datang, konsumen muslim merasakan enak dan berbeda dengan restoran lainnya sehingga menjadi tempat langganan ketika berlibur atau berwisata ke Bali. Mengenai pandangan konsumen terkait sertifikasi halal yang ada direstoran terutama di De Dapoer yaitu dengan adanya sertifikasi halal yang ada di De Dapoer - Rhadana Hotel Kuta Bali konsumen muslim lebih yakin, percaya, pelayanan nyaman, ramah-tamah, higienis, cukup terjamin, aman dan tanpa harus khawatir saat mengonsumsi makanan. Konsumen muslim tambah yakin dengan

\footnotetext{
${ }^{9}$ Derahman, Zamra dkk, Determinant Factor Of Consumers' Intention To Eat At Halal Certified Restaurant. Proceedings of $124^{\text {th }}$ The IIER International Conference : Tokyo Japan, 2017.
} 


\section{Persepsi Konsumen Muslim terhadap Sertifikasi Halal \\ pada De Dapoer Rhadana Hotel Kuta Bali}

dipajangnya sertifikat didinding dekat dengan resepsionis. sehingga menjadi daya jual tersendiri terutama De Dapoer - Rhadana Hotel Kuta Bali berada di masyarakat yang mayoritas non-muslim dan menjadikan strategi jitu bagi perusahaan dengan meyakinkan konsumen memasang label halal pada restorannya.

Responden yang mengetahui bahwa sertifikasi halal adalah jaminan halal yang dapat dijadikan bukti bahwa suatu produk sudah diteliti oleh lembaga yang berwenang atau MUI belum tentu mereka peduli ada atau tidaknya sertifikasi halal. Dan peneliti sengaja tidak langsung memberikan pertanyaan kepada responden terkait dengan "apakah sertifikasi penting menurut anda?" karena dikhawatirkan responden menjawab "penting". Ketika ditanyai pengetahuan tentang sertifikasi halal dan tahu atau tidaknya ditempat yang mereka kunjungi ada sertifikasi halalnya, hal ini bisa dijadikan bukti bahwa mereka menganggap adanya sertifikasi halal itu penting dan mempengaruhi seseorang saat berwisata dimana saja termasuk wilayah yang mayoritas masyarakatnya non-muslim. Peneliti mengklasifikasikan jawaban respondenyaitu responden menganggap atau berpersepsi bahwa adanya sertifikasi halal itu penting. Karena konsumen mengetahui bahwa sertifikasi adalah jaminan kehalalan suatu produk yang telah diterbitkan oleh MUI. Setelah dicek dan mereka tahu bahwa di De Dapoer Rhadana Hotel Kuta Bali ada sertifikasi halalnya.

Sehingga konsumen muslim dapat menilai untuk memilih rumah makan atau restoran yang halal dan sesuai dengan kebutuhan dari konsumen muslim. Salah satu caranya yaitu dengan mencari informasi terlebih dahulu seperti label sertifikasi halal yang ada di rumah makan atau restoran yang menunjukkan bahwa tempat tersebut telah mendapatkan sertifikasi halal dari MUI (Majelis Ulama Indonesia) yang menjadikan unsur penting bagi konsumen muslim dalam membeli makanan di rumah makan atau restoran teutama di Bali. Selain itu dengan adanya sertifikasi halal dapat memberikan jawaban apakah makanan yang dibelinya sudah aman dikonsumsi atau belum baik dari segi kesehatan maupun dari segi agama yang diyakininya.

\section{Kesimpulan}

Persepsi konsumen muslim terhadap sertifikasi halal yang ada pada De Dapoer Rhadana Hotel Kuta Bali beranggapan atau berpersepsi bahwa sertifikasi halal itu penting. Karena responden mengetahui bahwa untuk menjamin kehalalan suatu produk dengan cara adanya label sertifikasi halal. Hal ini dapat dilihat dari aspek pertama Kognitif atau pengetahuan terjaminnya kehalalan produk terlihat dari Konsumen muslim berpersepsi atau beranggapan bahwa alasannya memilih produk di De Dapoer - Rhadana Hotel Kuta Bali karena sudah tersertifikasi halal dan baik untuk dikonsumsi, menyediakan atau menyajikan makanan dan minuman halal serta aman untuk dikonsumsi. Konsumen muslim berpersepsi atau beranggapan bahwa produk yang ada di di De Dapoer - Rhadana Hotel Kuta Bali sudah terjamin kehalalannya karena non-alkohol, sudah ada sertifikasi halalnya dan cari tahu di google.

Kedua dari aspek Afektif atau keyakinan jaminan halal pada produk terlihat dari Ada 2 konsumen muslim berpersepsi atau beranggapan bahwa tidak menanyakan jaminan halal pada karyawan karena di google dan di restoran sudah tertera sertifikasi halal jadi memantapkan dan percaya. Dan ada 3 konsumen muslim berpersepsi atau beranggapan dengan menanyakan kepada karyawan mengenai jaminan halal respon dari karyawan baik, ramah, meyakinkan kalau memang halal dan alhmadulillah halal. Konsumen muslim berpersepsi atau berangggapan bahwa pandangannya mengenai sertifikasi halal yaitu membuktikan tempat itu halal, menyediakan barang-barang halal, minuman dan makanan halal, ditetapkan oleh MUI dan kehalalannya sudah diketahui, 
ditempel di dinding untuk membuktikan restoran sudah terjamin kehalalannya serta sertifikat yang dikeluarkan oleh MUI yang menunjukkan bahwa produk benar-benar halal.

Ketiga dari aspek Konatif atau melakukan tindakan mengonsumsi produk halal. Konsumen muslim berpersepsi atau beranggapan bahwa di De Dapoer sudah tersertifikasi halal dari google atau internet, browsing dan rekomendasi dari teman. Konsumen muslim berpersepsi atau beranggapan bahwa pandangannya terhadap sertifikasi halal yang ada di De Dapoer yaitu makanan dan minuman sudah tersertifikasi halal, non- alkohol, yakin, percaya, pelayanan nyaman, ramah-tamah, higienis, cukup terjamin saat menikmati makanan tanpa harus khawatir dan menyakinkan dengan dipajangnya sertifikasi halal di dinding dan daya jual di mayoritas non-muslim serta strategi jitu meyakinkan konsumen dengan memasang label halal.

\section{Daftar pustaka}

Ashari, Mela. 2019. Pengaruh Pengetahuan Produk dan Sertifikasi Halal Terhadap Keputusan Pembelian Produk Farmasi Di Desa Mojorejo Kecamatan Kebunsari Kabupaten Madiun. Skripsi. Surabaya: Universitas Islam Negeri Sunan Ampel

Barkatulah, Abdul Halim. 2008. Hukum Perlindungan Konsumen (Kajian Teoritis dan Perkembangan Pemikiran). Bandung: Nusa Media

Daru, Nadia WulandanMoch. Khoirul Anwar. 2019. Persepsi Konsumen Muslim Terhadap Produk MS Glow Yang Bersertifikat Halal di Surabaya. Jurnal Ekonomi Islam. Vol. 2 No. 2 Hal. 15-24. Surabaya: Program Studi Ekonomi Islam Fakultas Ekonomi Universitas Negeri Surabaya

Derahman, Zamra dkk. 2017. Determinant Factor Of Consumers' Intention To Eat At Halal Certified Restaurant. Proceedings of $124^{\text {th }}$ The IIER International Conference: Tokyo Japan

Hafizi, Muhammad Riza., dan Rimbodo, Dyah Sulistiyo., (2019), Pengelolaan Bisnis Perhotelan Syariah, At-Tijaroh: Jurnal Ilmu manajemen dan Bisnis Islam, Vol. 5, No. 1, pp. 52-66, doi: https://doi.org/10.24952/tijaroh.v5i1.1631

Kotler dan Armstrong. 2008. Dasar-dasar Pemasaran. Jakarta: Indeks Gramedia

Kotler, Philip. 2002. Manajemen Pemasaran Edisi Milenium Jilid 2. Jakarta: PT. Prenhallindo

Lexy J. Moleong. 2009. Metodologi Penelitian Kualitatif. Bandung: PT. Remaja Rosdakarya.

Lubis, Nurul Izzah. (2019), Analisis Loyalitas Konsumen Produk Berlabel Halal, Jurnal

Al-Qardh, Vol. 4, No. 1, pp. 51-59, doi: https://doi.org/10.23971/jaq.v4i1.1661

Mahanani, Astyasari Esti. 2017. Persepsi Konsumen Terhadap Kualitas Produk dan Pelayanan Di Rumah Makan Moro Sakeco Grabag Magelang. Skripsi. Yogyakarta: Program Studi Pendidikan Teknik Boga Fakultas Teknik Universitas Negeri Yogyakarta

Milles, Matthew B. dan Haberman, Michael A. 2009. Analisis Data Kualitatif. Tjetjep Rohendi Rohini, Penerjemah. Jakarta: Universitas Indonesia. Terjemah dari: UI- PRESS

Napitasari, Amarinda. 2018. Analisis Minat Beli Konsumen Pada Restoran Bersertifikasi Halal MUI Di Daerah stimewa Yogyakarta Tahun 2018. Skripsi. Yogyakarta: Jurusan pendidikan Ekonomi Fakultas Ekonomi Universiras Negeri Yogyakarta 
Nasution, Az. 2001. Hukum Perlindungan Konsumen Suatu Pengantar. Jakarta: Diadit Media Noor, Aziza dan Febrina Rosinta. 2013. Analisis Persepsi Konsumen Terhadap Tagline Restoran D'Cost Seafood. Jurnal. Depok: Program Studi Administrasi Niaga Fakultas Ilmu Sosial dan Ilmu Politik universitas Indonesia

Nurcahyo, Agung dan Hudrasyah, Herry. 2017. The Influence Of Halal Awareness, Halal, Certification, And Persoanl Societal Perception Toward Purchase Intention: A Study Of Instant Noodle Consumption Of Collage Student In Bandung. Jurnal Of Business and Management Vol. 6 No. 1. Bandung: Institut Teknologi Bandung

Pambudi, Bonus Giwang. 2018. Pengaruh Kesadaran Halal dan Sertifikasi Halal Terhadap Minat Beli Produk Mie Instan (Studi Pada Pemuda Muslim Bandar Lampung). Skripsi. Bandar Lampung: Universitas Lampung

Pelu, I. E. A., Kurniawan, R., \& Akbar, W. (2020). Developing Sharia Tourism in Fostering Regional Economic Growth (Study on Sharia Tourism at West Nusa Tenggara). Heritage of Nusantara: International Journal of Religious Literature and Heritage, 9(1), pp. 115-142. https://doi.org/10.31291/hn.v9i1.562

Qomaro, Galuh Widiya. 2018. Sertifikasi Halal Dalam Persepsi Konsumen Pada Produk Pangan Di Kabupaten Bangkalan. Jurnal madura: Universitas Trunojoyo

Rahmaniar., Farid, F.M., dan Herliani, Yeni. (2017), Pengaruh Perilaku Konsumen dan Label Halal Produk Makanan Rumah Tangga terhadap Keputusan Konsumsi di Palangka Raya, Jurnal Al-Qardh, Vol. 2, No.1, pp. 60-65, doi: https://doi.org/10.23971/jaq.v2i1.827

Ruslan, A.A.A., Kamarulzaman, N.H., dan Sanny, M. 2018. Muslim Consumers' Awareness and Perception of Halal Food Fround. International Food Research Journal 25(Suppl.1): S87-S96

Saaidin, Muniara dkk. 2018. Muslim Consumers' Perception of Service Quality for Halal Food Service Indusutry. International Journal of Academic Research $\mathrm{n}$ Business and Sosial Sciences ISSN: 2222-6990 Vol. 8 No. 9

Schifman, Leon G, Kanuk, Leslie Lazar. 2008. Perilaku Konsumen, Jakarta:PT Indeks Group Media.

Sholeh, Aufa Saffanah Fitri. 2018. Penerapan Prinsip Syariah Pada Bayt Kaboki Hotel Bali Menurut Fatwa DSN MUI No. 108/DSN MUI/X/2016. Skripsi. Jakarta: Program Studi Hukum Ekonomi Syariah (Muamalat) Fakultas Syariah dan Hukum Universitas Islam Negeri Syarif Hidayatullah

Subakti, Agung Gita. dkk. 2018. Analisis Persepsi Konsumen.Tourism and Hospitaly Essentials (THE) Journal. Vol. 8 No. 1 Hal. 31. Jakarta: Universitas Bina Nusantara

Sugiono. 2008. Memahami Penelitian Kualitatif. Bandung: Alfabeta Sugiyono. 2008. Memahami Penelitian Kualitatif. Bandung: Alfabeta

Wahyuni, Meika. 2015. Persepsi Konsumen Muslim Terhadap Sertifikasi Halal. Skripsi. Semarang: Jurusan Ekonomi Islam Fakultas Ekonomi dan Bisnis Universitas Islam Negeri Walisongo

Walgito. 1999. Psikologi Sosial (Suatu Pengantar). Yogyakarta: Andi Yogyakarta Walgito. 2002. Pengantar Psikologi Umum. Yogyakarta: Andi Offset.

Zaimah, R., dkk. 2018. Consumers' Perceptions and Behaviours Towards Halal Food Products in Malaysia. International Journal of Academic Research n Business And Sosial Sciences ISSN: 2222-6990 Vol. 8 No. 13 